Escuela de Ciencias Sociales y Humanidades, UNED, C.R.

URL: http://investiga.uned.ac.cr/revistas/index.php/espiga/index

DOI: http://dx.doi.org/10.22458/re.v16i33.1663

ISSN: 1409-4002 • e-ISSN: 2215-454X

\title{
Blanqueo de activos: la experiencia costarricense
}

\author{
Arturo Azofeifa-Céspedes *
}

Recibido: 18 de enero, 2015 - Aceptado: 19 de setiembre, 2016 - Corregido: 30 de noviembre, 2016

\section{RESUMEN}

(Find the abstracts in English and French at the end of the article)

El propósito de este trabajo es demostrar que la legitimación de activos representa un problema que debilita gobiernos, afecta economías, deteriora a la sociedad, genera corrupción y aumentos significativos en la violencia, por ende contribuye a la inseguridad ciudadana, aun cuando las autoridades policiales hagan sus mayores esfuerzos para combatir este flagelo. Cualquier ciudadano debe ser capaz de entender que eventualmente puede sufrir las consecuencias del problema y debe ser consciente de que debe aportar su granito de arena para luchar contra este delito. La lucha internacional contra la legitimación de activos demuestra que únicamente se puede ganar si cada ser humano, mediante la concienciación, reconoce en sus valores y en su aporte individual, las armas más poderosas para batallar contra este mal.

Palabras clave: legitimación, activos, drogas, narcotráfico, lavado, dinero, sociedad, seguridad, problemática, prevención.

\section{Formato de citación según APA}

Azofeifa-Céspedes, A. (2016). Blanqueo de activos: la experiencia costarricense. Revista Espiga, 16(33), 107-130. DOI: http://dx.doi.org/10.22458/re.v16i33.1663

\section{Formato de citación según Chicago}

Azofeifa-Céspedes, Arturo. «Blanqueo de activos: la experiencia costarricense». Revista Espiga. 16. № 33 (2016): 107-130. DOI: http://dx.doi.org/10.22458/re.v16i33.1663

* Auditor Financiero Forense. Especialista en Anti-lavado de Activos. Profesor de la Cátedra Ciencias Policiales. Universidad Estatal a Distancia (UNED). Costa Rica. aazofeifa@uned.ac.cr 


\section{Introducción}

La actualidad costarricense no es ajena ni diferente a la actualidad latinoamericana, en cuanto a los temas del narcotráfico y las luchas armadas de los cárteles de las drogas. Es habitual ver o leer las noticias y enterarse no solamente de grandes decomisos de drogas, sino de los diferentes crímenes vinculantes a este negocio, como lo son los asesinatos, los ajusticiamientos, la corrupción, entre otros.

Parte de la importancia de las instituciones pertenecientes al sector financiero de cada país, no es solamente contribuir a su economía, sino que también deben acatar estrictamente las leyes y todo lo referente al derecho, sea este público o privado. Es deber de estas instituciones implementar los mecanismos necesarios para evitar que los dineros mal habidos o ilícitos, ingresen a sus arcas y así velar porque sus productos o servicios no sean motores del desarrollo y crecimiento de la industria delictiva mundial.

El problema de la legitimación de activos y el financiamiento del terrorismo, trasciende el hecho de estar o no, listado como un país no cooperador o un paraíso fiscal, que de por sí ya trae problemas para la imagen y reputación del país, también puede desbalancear gobiernos y economías enteras.

Más allá de definiciones pomposas, llenas de florituras y tecnicismos, la legitimación de activos no es otra cosa que tomar el producto de una actividad ilícita y darle apariencia de legitimidad, y el terrorismo es el uso sistemático del terror para obtener objetivos políticos, religiosos e ideológicos.

Según el Instituto Costarricense sobre Drogas (ICD), los esfuerzos realizados por Costa Rica en los últimos años se han traducido en dos áreas: en un incremento de los decomisos de drogas que alcanzaron en el período 2009-2011, 39,79 toneladas de clorhidrato de cocaína, 570016 dosis de crack, 5535663 plantas de Cannabis, 4,2 toneladas de picadura de marihuana y 19973 dosis de éxtasis; así como, en un aumento de las organizaciones criminales desarticuladas.

Las cifras anteriores no se justifican solamente a causa de una mayor eficiencia de las autoridades encargadas de la represión del tráfico, sino simplemente a que Costa Rica se ha convertido en la vía de paso, por aire, mar y tierra de la droga hacia Estados Unidos entre otros destinos existentes. Se estima que la relación entre droga capturada y el total del tráfico a través del país es de 1 a 10.

El tráfico de droga aumenta naturalmente la delincuencia en el país, en especial aumenta la violencia de los delitos. Las luchas entre grupos delictivos y pandillas por territorio para la venta interna de las drogas provocan cada vez más muertes.

\section{Definición de lavado de dinero}

Según ACAMS, se entiende como lavado de dinero o legitimación de activos:

(...) El proceso de hacer que el dinero sucio parezca limpio. El objetivo de estos crímenes es generar ganancias para el individuo o grupo que realiza los actos delictivos. El lavado de dinero es el procesamiento de esos fondos criminales para ocultar su fuente ilegal. Es de importancia 
crucial, dado que le permite al delincuente tener los beneficios de esas ganancias sin poner en peligro su fuente.

El lavado de dinero puede ser definido, generalmente, como el proceso de ocultamiento de la existencia, la fuente ilegal o la aplicación de ingresos obtenidos provenientes de actividades criminales, y el subsiguiente ocultamiento de la fuente de esos ingresos para hacerlos aparecer como legítimos. También, es cualquier tentativa por ocultar o disfrazar la identidad de los fondos obtenidos ilegalmente de manera que aparezcan como originados en fuentes legítimas. ${ }^{1}$

Básicamente, legitimar activos es tomar el producto de una actividad ilícita para darle apariencia de legalidad, entendiéndose como una actividad ilícita cualquier actividad tipificada contraria a la Ley vigente.

\section{Sinónimos de lavado de dinero}

Dependiendo de la normativa, la traducción, el país y otros factores, existen diferentes sinónimos para referenciar a la legitimación de activos. Algunos son:

- Lavado de activos

- Blanqueo de activos

- Reciclaje de dinero sucio

- Lavado de capitales ilícitos

- Legalización y ocultamiento de bienes provenientes de actividades ilegales

- Lavado de dinero

- Legitimación de activos

- Legitimación de capitales

Es más apropiado el término "legitimación de activos", dado que es este el que más aproximadamente ilustra el objetivo del ilícito, además que tanto el dinero como el capital son activos.

\section{Autonomía del delito}

A pesar de que la legitimación de activos requiere de un delito precedente para producir el dinero por legitimar, para su juzgamiento es un delito independiente; es decir, el narcotráfico es un delito y la legitimación de activos es otro. Por ejemplo, quien vende droga y con el producto de esa venta adquiere bienes o ingresa esos recursos a cualquier institución perteneciente al sistema financiero nacional, para ocultar su origen delictivo,

1. Asociación de Especialistas Certificados en Antilavado de Dinero, Guía de estudio para el examen de certificación CAMS (Miami: Acams, 2007), 4. 
al menos comete dos delitos. Es decir, la venta de droga es un delito por sí solo, e ingresar ese dinero para ser escondido es otro.

En la realidad, y al ser un delito de mera actividad, la sola posesión de droga es mucho más fácil de probar que la naturaleza ilícita del dinero que se posee, probar la legitimación de activos generalmente es muy complejo y requiere meses o años de trabajo que incluso muchas veces arroja resultados poco alentadores.

Complementando lo anterior Hannia Soto Arroyo expresa:

Cabe indicar, respecto a la situación particular de Costa Rica, que el delito de blanqueo de capitales si bien se juzga de forma independiente, sí debe tener como origen una acción delictiva, por lo que, como veremos más adelante, jurisprudencialmente se ha establecido que debe demostrarse el origen ilícito de los dineros que se tratan de blanquear, para reprochar penalmente al autor. ${ }^{2}$

\section{Etapas en el ciclo del lavado de dinero}

El lavado de dinero inicia cuando por medio de un ilícito se produce algún activo del cual es necesario ocultar su procedencia. Desde el punto de vista policial, el lavado de dinero debería iniciar desde el delito que lo origina, pero desde el punto que atañe a las instituciones financieras, inicia desde que el dinero es llevado a sus oficinas, agencias o sucursales para tratar de ser introducido en la propia entidad.

Desde esa última perspectiva es posible reconocer tres etapas fundamentales:

Colocación: El dinero producto de una actividad ilícita se trata de ocultar, mezclándose muchas veces con dinero lícito, en cuanto es llevado a la entidad financiera para adquirir algún producto o servicio financiero.

Estratificación: El dinero ingresa a la entidad financiera y comienza a ocultar su origen ilícito, aquí directa o indirectamente se ha vulnerado el control anti-lavado.

Integración: El dinero tiene la apariencia legítima que necesita y ya está listo para volver a la economía para adquirir bienes y servicios, para mantener vidas lujosas o para reinvertirse en el crimen organizado.

En la figura 1 se describe el comportamiento típico del dinero proveniente de alguna actividad ilícita, por ende son recursos que deben ser legitimados, básicamente por dos grandes razones para el delincuente o crimen organizado. La primera es para evitar privarse de este para su disfrute o para seguir financiando las actividades delictivas, y la otra para que los perpetradores no sean encarcelados dado su vínculo con el propósito criminal.

2. Hannia Soto Arroyo, «El delito de legitimación de capitales a la luz de la legislación y la jurisprudencia penal costarricense.» Revista Electrónica de la Facultad de Derecho, ULACIT, 2012: 59-81. 


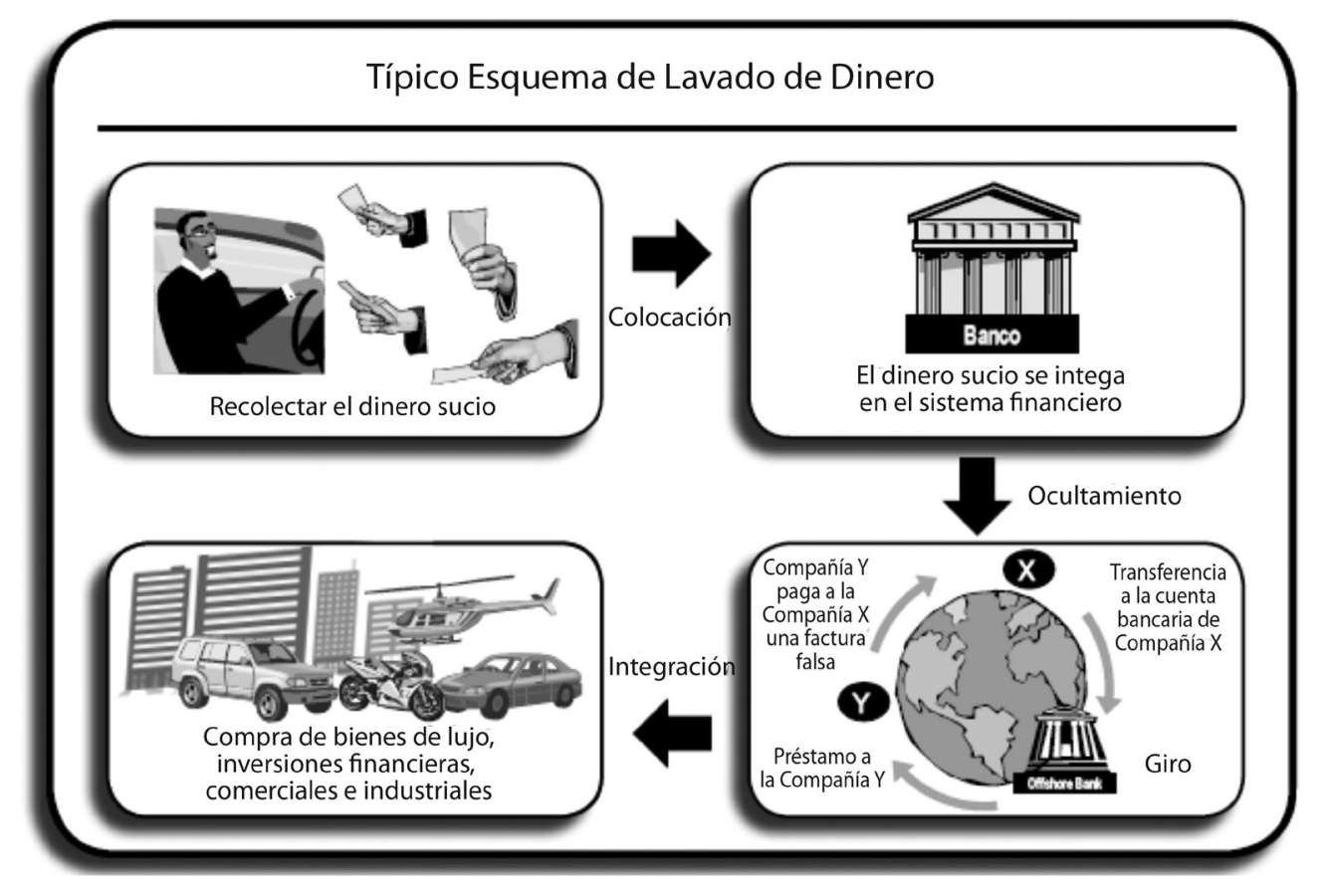

Figura 1. Típico esquema de lavado de dinero. Fuente: Oficina de las Naciones Unidas Contra la Droga y el Delito. Tomado de la Guía de estudio para el examen de certificación CAMS (Asociación de Especialistas Certificados en Antilavado de Dinero 2007).

Durante la etapa de colocación, el dinero después de ser obtenido se lleva a las instituciones para intentar que sea ingresado mediante algún producto o servicio financiero que se ofrezca, así durante el ocultamiento o la estratificación, que es la segunda etapa del esquema, el dinero mal habido se mezcla con el de naturaleza legítima, dando con esto la mampara perfecta, y en la etapa de integración, los activos financieros pueden volver a la economía para su utilización o reinversión.

\section{Tipologías}

Algunas de las técnicas, métodos o tipologías utilizadas para legitimar activos:

- Estructuración (Pitufeo): Planificar bien la cantidad de dinero por depositar no debe alcanzar el límite para generar el reporte de cumplimiento normativo, en el caso de Costa Rica el reporte de operación en efectivo (ROE).

- Sobrefacturación y subfacturación: Facturar más o menos según sea la conveniencia.

- Exportación ficticia de bienes y servicios: Envío de material, mercancía o dación de servicios inexistentes.

- Inversión extranjera ficticia: Dinero proveniente de supuestos inversionistas extranjeros. 
- Doble facturación: Registra dos o más veces la venta de activos o productos.

- Compra de premios: Compra de billetes o enteros de lotería.

- Creación de asociaciones y fundaciones: Fuente de recursos (donaciones) y anonimato de donantes, aparente bondad del destino.

- Donaciones: El lavador opera como donante o donatario, la donación justifica la transferencia.

- Compra y venta de bienes: Intercambio rápido de bienes.

Se pueden citar infinidad de tipológicas, pero se debe considerar que todos los productos y servicios financieros, además de otras actividades comerciales, presentan oportunidades para la comisión del delito, también el crimen organizado, la globalización y la internacionalización aportan complejidad a esta situación.

Al respecto, Lubi González, Edwards Carvajal y Linda Chacín, basados en su estudio: «Líneas de acción aplicadas en la prevención y control de la legitimación de capitales en la banca universal venezolana», resaltan que "Las organizaciones delictivas operan hoy día en alianza cada vez más extendida con grupos internacionales, con el fin de lograr comercializar y distribuir los productos provenientes de sus actividades ilícitas". ${ }^{3}$

Enriqueciendo lo anterior, Daniel Pontón agrega:

Los ingresos económicos de estas economías pueden venir del desarrollo de distintas actividades completamente ilegales o ilegales con apariencia legal. Pese a esta diversidad, el tráfico de drogas es de largo la actividad ilegal que mayor poderío económico representa internacionalmente, lo cual hace de este mercado el motor financiero de las principales organizaciones criminales en el mundo. ${ }^{4}$

\section{Consecuencias del lavado de dinero}

Las consecuencias para la sociedad derivadas de la legitimación de capitales se presentan en diferentes áreas que se mencionan a continuación:

En primer lugar, las sociales, como el aumento de la violencia callejera, la generación de corrupción, la lucha de pandillas por el control de la droga, la desintegración de las familias, la drogadicción, la inseguridad ciudadana, que deterioran la moral social y producen efectos sociales dañinos, entre otras.

En segundo lugar, las económicas: el aumento de los índices de desempleo, el desequilibrios en la balanza de pagos del país, la disminución de la inversión extranjera, la

3. Lubi González, Edwards Carvajal y Linda Chacín, «Líneas de acción aplicadas en la prevención y control de la legitimación de capitales en la banca universal venezolana.» Revista COEPTUM, 2014: 1-14.

4. Daniel Pontón C., «La economía del narcotráfico y su dinámica en América Latina.» Revista Íconos, (2013): 135-153. 
inflación, el descontrol en los tipos de cambio, la redistribución regresiva de la riqueza, la competencia desleal, la devaluación de la moneda, entre otras.

En tercer lugar, las financieras: descalce de plazos, desconfianza en el sector financiero, quiebras, iliquidez, descapitalización, mecanismos de evaluación multilateral, impacto según organismos internacionales, desconfianza del público y de los inversionistas, entre otras.

En cuarto lugar, las legales: multas, inhabilitación del ejercicio liberal de la profesión, extrañamiento, sanciones penales y administrativas, entre otras.

Finalmente, las internacionales o las relacionadas con el comercio exterior: las barreras al comercio internacional, riesgo de imagen, pérdida de ventajas competitivas, fuga de empresas extranjeras, baja en las calificaciones de riesgo, daño en la imagen internacional, entre otras.

Bajar la guardia, descuidarse, pensar que esto no pasará en nuestra institución, que no nos pasará a nosotros son precisamente acciones o situaciones consideradas como algunos de los mitos relacionados con la legitimación de activos, y son precisamente esas malas prácticas las que inducen al error e indirectamente contribuyen a la comisión de la legitimación de activos.

\section{Mitos relacionados con la legitimación de activos}

Es frecuente subdimensionar el daño que realmente causa el dinero ilícito en el mundo en general, no constituye historias imaginarias ni ajenas a la realidad que se vive en países que sufren este mal, tampoco son cuentos propios de la fantasía y de la creatividad de unos pocos.

Un mito relacionado con la legitimación de activos es una falacia preventiva, es una acción u omisión que inicialmente no parece riesgosa, pero su existencia supone un peligro latente que va consumiendo los sistemas preventivos y de control interno, otras veces surgen de creencias sociales y culturales justificadas en una falsa seguridad derivada del desconocimiento total de la realidad nacional, regional e incluso mundial y de la vulnerabilidad de entidades y de gobiernos en desventaja contra el crimen organizado.

También la negligencia, la impericia y la imprudencia son factores claves de su existencia, supervivencia y prosperidad.

Entre algunos de estos mitos se pueden encontrar:

- No puede pasarnos a nosotros.

- Somos una organización estable.

- Los daños no serían significativos.

- Nuestra gente no lo haría.

- Estamos suficientemente protegidos. 
- Vigilamos las áreas vulnerables.

- Sabríamos si hubiera ocurrido.

- Si ocurre sería descubierto rápidamente.

Estos mitos son el terreno fértil en que se cosechan verdaderas amenazas para los responsables en la lucha contra la legitimación de activos y para los gestores preventivos de las entidades reguladas, son, por mucho, los enemigos declarados, constantes y siempre presentes de la buena gestión de cumplimiento.

\section{Enemigos de la buena gestión preventiva}

Existen cualidades y competencias propias del buen ejecutante preventivo, atributos que deberían facilitar las gestiones y la consecución del gran objetivo que es detectar los recursos que se originan de actividades ilícitas y evitar su ingreso. No obstante, como cualquier actividad humana incluso profesional, existen prácticas, costumbres, procesos y hasta procedimientos que son opuestos al buen funcionamiento de los mecanismos preventivos y hasta de las buenas prácticas internacionales, son estos los verdaderos enemigos de la buena gestión preventiva.

Se enumeran a continuación algunos enemigos de la gestión preventiva, seguidos de prácticas para disminuir su ocurrencia:

- Miopía: Hacer siempre lo mismo sin razonamiento ni autocrítica.

- Confianza: Confiar en exceso.

- Protagonismo: Lo importante es la gestión, no quien haga la gestión.

- Desconocimiento: Conocer el negocio, no se trata de que no ingrese dinero, se trata de saber que no ingresó dinero mal habido.

- Desactualización: Mantenerse actualizado en cuanto a las nuevas tipologías, técnicas o formas para legitimar capitales.

No existe institución financiera en el mundo capaz de afirmar ser inmune al problema de la legitimación de activos. Al final, y ante la materialización de algún caso, lo que debe probarse es la verdadera aplicación o apego a una diligencia debida, demostrando con esto la buena fe de la administración y su compromiso con la prevención, la existencia de controles y la evidente razón por la cual los controles fallaron, en caso de error comprobado.

La única cura o protección que existe contra estos enemigos es la intolerancia a su ocurrencia, se deben conocer para ser capaces de reaccionar ante su materialización, y se debe huir y reaccionar frente a su presencia, no se debe soportar su existencia.

Al respecto, Juan Manuel del Cid Gómez manifiesta:

Las medidas de debida diligencia también se centran en la obtención de información sobre el propósito de la relación de negocios y la aplicación de medidas de seguimiento continuo a 
dicha relación, incluido el escrutinio de transacciones, a fin de garantizar que coinciden con el conocimiento que se tenga del cliente y de su perfil y el origen de los fondos. ${ }^{5}$

Algunos compromisos y riesgos de los principales actores ante la prevención de la legitimación de activos.

El siguiente cuadro resume los compromisos y los principales riesgos que necesariamente poseen o deberían asumir los actores activamente involucrados en la prevención de la legitimación de activos y el financiamiento al terrorismo, no se incluyen los que por normativa han sido establecidos, sino los que se consideran complementarios o más tangibles para ciudadanos o funcionarios quienes día con día y mediante su quehacer combaten directamente estos ilícitos.

\section{CUADRO 1}

Compromisos y riesgos de los principales actores ante la prevención de la legitimación de activos y el financiamiento al terrorismo

\begin{tabular}{|c|c|c|}
\hline Actor & Compromiso & Riesgo \\
\hline Gobierno & $\begin{array}{l}\text { 1. Velar y garantizar la cooperación global con los organismos } \\
\text { nacionales e internacionales en la lucha contra el lavado de } \\
\text { dinero y el financiamiento al terrorismo. } \\
\text { 2. Brindar a los actores los recursos necesarios para que puedan } \\
\text { realizar todas y cada una de las acciones o gestiones que se } \\
\text { espera de ellos. } \\
\text { 3. Establecer estándares éticos y morales muy altos para quienes } \\
\text { ocupan puestos estratégicos y con esto requerir una solvencia } \\
\text { moral mínima. }\end{array}$ & $\begin{array}{l}\text { 1. Pérdida de confianza por parte de } \\
\text { ciudadanos. } \\
\text { 2. Ingobernabilidad. } \\
\text { 3. Mala reputación internacional. } \\
\text { 4. Acceso a financiamiento } \\
\text { internacional. } \\
\text { 5. Presencia en listas grises o negras. } \\
\text { 6. Aumento de la criminalidad en el } \\
\text { territorio. } \\
\text { 7. Inflación. } \\
\text { 8. Caída de la inversión extranjera. } \\
\text { 9. Desempleo. } \\
\text { 10. Deterioro social. }\end{array}$ \\
\hline Poder Legislativo & $\begin{array}{l}\text { 1. Crear o modificar oportunamente la normativa que será utiliza- } \\
\text { da como herramienta preventiva principal para todos los actores } \\
\text { en el mecanismo de la prevención de la legitimación de activos y } \\
\text { el financiamiento al terrorismo. }\end{array}$ & $\begin{array}{l}\text { 1. Pérdida de confianza por parte de los } \\
\text { ciudadanos. } \\
\text { 2. Ingobernabilidad. } \\
\text { 3. Aumento de la criminalidad en el } \\
\text { territorio. } \\
\text { 4. Desempleo. } \\
\text { 5. Deterioro social. }\end{array}$ \\
\hline
\end{tabular}

5. Juan Manuel del Cid- Gómez, «Prevención del blanqueo de capitales. Un enfoque basado en el riesgo para contables externos y asesores fiscales.» Partida Doble, 2009: 74-81. 


\begin{tabular}{|c|c|c|}
\hline Actor & Compromiso & Riesgo \\
\hline Poder Ejecutivo & $\begin{array}{l}\text { 1. Ejecutar puntualmente y sin demora las decisiones del } \\
\text { poder legislativo. }\end{array}$ & $\begin{array}{l}\text { 1. Pérdida de confianza por parte de los } \\
\text { ciudadanos. } \\
\text { 2. Ingobernabilidad. } \\
\text { 3. Aumento de la criminalidad en } \\
\text { el territorio. } \\
\text { 4. Desempleo. } \\
\text { 5. Deterioro social. }\end{array}$ \\
\hline $\begin{array}{l}\text { Instituto Cos- } \\
\text { tarricense sobre } \\
\text { Drogas }\end{array}$ & $\begin{array}{l}\text { 1. Optimizar las prácticas antilavado en los aspectos de prevención, } \\
\text { detección y combate. } \\
\text { 2. Emitir disposiciones para que los sujetos obligados establezcan } \\
\text { mecanismos que les permitan identificar y anticipar posibles } \\
\text { comportamientos ilícitos e inusuales relacionados con el lavado } \\
\text { de dinero y el financiamiento al terrorismo. } \\
\text { 3. Realizar campañas y cualquier otro material publicitario que } \\
\text { contribuya a informar al ciudadano sobre la importancia de no } \\
\text { consumir drogar ilícitas, además de que conozcan el papel que } \\
\text { deben asumir ante la prevención de los delitos. } \\
\text { 4. Emitir estadísticas que permitan alimentar matrices y modelos } \\
\text { de riesgo de las entidades reguladas. } \\
\text { 5. Realizar programas y destinar los recursos para que sean utiliza- } \\
\text { dos en la rehabilitación de las personas farmacodependientes. } \\
\text { 6. Asignar los recursos necesarios para que otros actores realicen } \\
\text { adecuadamente sus gestiones o funciones. }\end{array}$ & $\begin{array}{l}\text { 1. Pérdida de confianza por parte de los } \\
\text { ciudadanos. } \\
\text { 2. Ingobernabilidad. } \\
\text { 3. Aumento de la criminalidad en } \\
\text { el territorio. } \\
\text { 4. Desempleo. } \\
\text { 5. Deterioro social. }\end{array}$ \\
\hline Superintendencias & $\begin{array}{l}\text { 1. Defender y garantizar la credibilidad en el sistema fi- } \\
\text { nanciero nacional. } \\
\text { 2. Emitir estadísticas que permitan alimentar matrices y modelos } \\
\text { de riesgo de las entidades reguladas. } \\
\text { 3. Brindar o gestionar capacitación y asesoría a las enti- } \\
\text { dades reguladas. } \\
\text { 4. Realizar informes o publicaciones que contribuyan al fortaleci- } \\
\text { miento de una política colaborativa y preventiva nacional. } \\
\text { 5. Asesorar a las entidades reguladas en las mejores } \\
\text { prácticas preventivas. }\end{array}$ & $\begin{array}{l}\text { 1. Pérdida de confianza por parte de los } \\
\text { ciudadanos. } \\
\text { 2. Pérdida de confianza en el sistema } \\
\text { financiero. } \\
\text { 3. Ingobernabilidad. } \\
\text { 4. Aumento de la criminalidad en } \\
\text { el territorio. } \\
\text { 5. Desempleo. } \\
\text { 6. Deterioro social. }\end{array}$ \\
\hline
\end{tabular}




Actor Compromiso Riesgo

Entidades 1. Ser fieles cumplidores de la normativa interna y externa referente Financieras a la prevención de la legitimación de activos, financiamiento al terrorismo y cualquier otro delito que pueda desestabilizar a la región, al gobierno o hasta el propio sistema financiero nacional o internacional.

2. Mantener capacitado a todo el personal en técnicas actualizadas preventivas.

3. Cooperar con las autoridades administrativas y judiciales del país.

4. Reportar inmediatamente cualquier actividad sospechosa de directivos o colaboradores a las autoridades competentes.

Universidades 1. Generar nuevo conocimiento útil para todos los actores, mediante inversión en investigación y propiciando la publicación de artículos académicos, ensayos y libros.

2. Velar que tanto estudiantes como personal administrativo y docente cuenten con una formación humanística y ética útil como filtro para lo que se espera de ellos.

3. Tener una oferta académica útil para los actores, que les permita fortalecer sus conocimientos según sus respectivos roles.

1. Establecer estándares éticos altos que regulen y guíen el ejercicio aceptable y adecuado de la profesión.

2. Brindar o coordinar las acciones formativas que se traduzcan en herramientas preventivas reales para sus colegiados.

3. Sancionar a todo aquel que incumpla o se preste directa o indirectamente para actos contrarios a la ley y a las buenas prácticas profesionales.

\section{Colegios}

Profesionales
1. Potenciales sanciones administrativas, pecuniarias o penales.

2. Quiebra o cierre de operaciones.

3. Pérdidas económicas.

4. Cierre banca corresponsal.

\section{Pérdida de confianza por parte de} los ciudadanos.

2. Ingobernabilidad.

3. Acceso a financiamiento internacional.

4. Aumento de la criminalidad en el territorio.

5. Desempleo.

6. Deterioro social.

1. Pérdida de confianza por parte de los ciudadanos y profesionales colegiados.

2. Pérdida de credibilidad en la profesión.

3. Disminución de cantidad de colegiados.

4. Aumento de la criminalidad en el territorio.

5. Desempleo.

6. Deterioro social. 


\begin{tabular}{|c|c|c|}
\hline Actor & Compromiso & Riesgo \\
\hline Docentes & $\begin{array}{l}\text { 1. Dentro del currículo debe enseñarse sobre la necesidad de ser } \\
\text { buenos ciudadanos, cumplidores de cualquier normativa, ley o } \\
\text { incluso regla del hogar relacionada con el respeto o la considera- } \\
\text { ción con el derecho y bienestar de los demás. } \\
\text { 2. Deben ser conscientes y comprometidos en enseñar la capaci- } \\
\text { dad de cambiar las cosas sin anteponer cualquier interés frívolo } \\
\text { personal antes del bien general, y así las situaciones lleguen a } \\
\text { cambiar para bien. } \\
\text { 3. Debe creer, sin prejuicios, que cualquiera de los estudiantes, si } \\
\text { se lo propone, puede generar un efecto multiplicador positivo de } \\
\text { cambio que debe empezar en sí mismo contagiando a su familia } \\
\text { inmediata. }\end{array}$ & $\begin{array}{l}\text { 1. Aumento de la violencia y de la } \\
\text { inseguridad. } \\
\text { 2. Corrupción. } \\
\text { 3. Desempleo. } \\
\text { 4. Cárcel. } \\
\text { 5. Desintegración familiar. } \\
\text { 6. Drogadicción. } \\
\text { 7. Muerte. }\end{array}$ \\
\hline Profesionales & $\begin{array}{l}\text { 1. Mantenerse actualizados en materia preventiva y en tipologías } \\
\text { del delito. } \\
\text { 2. Ser estrictos cumplidores de las imposiciones legales y éticas que } \\
\text { los cobijan. } \\
\text { 3. Mantener una sana lealtad con otros colegas. } \\
\text { 4. Hacer del conocimiento de las autoridades competentes cual- } \\
\text { quier actividad o comportamiento sobre los que se sospeche } \\
\text { exista una eventual legitimación de activos o financiamiento al } \\
\text { terrorismo. }\end{array}$ & $\begin{array}{l}\text { 1. Inhabilitación temporal del ejercicio } \\
\text { profesional. } \\
\text { 2. Sanciones administrativas o penales. } \\
\text { 3. Modificación del modus vivendi } \\
\text { personal y familiar. } \\
\text { 4. Rechazo social. } \\
\text { 5. Mala reputación. }\end{array}$ \\
\hline Ciudadanos & $\begin{array}{l}\text { 1. Ser estrictos cumplidores de las leyes o normativa vigente. } \\
\text { 2. Enseñar valores éticos y morales a los miembros de su familia. } \\
\text { 3. Denunciar cualquier actividad delictiva que conozcan. } \\
\text { 4. Concienciarse sobre las personas a quienes eligen para ejercer } \\
\text { puestos de autoridad o políticos. } \\
\text { 5. Involucrarse con actividades curriculares y extracurriculares de } \\
\text { los miembros de su familia, es decir qué aprenden en la escuela o } \\
\text { colegio y qué hacen cuando no están en ésta. } \\
\text { 6. Enseñar la importancia del trabajo digno y honrado. } \\
\text { 7. Involucrarse con las decisiones comunales, no dejando a los } \\
\text { demás las decisiones que afectan a todos. }\end{array}$ & $\begin{array}{l}\text { 1. Aumento de la violencia y de la } \\
\text { inseguridad. } \\
\text { 2. Corrupción. } \\
\text { 3. Desempleo. } \\
\text { 4. Cárcel. } \\
\text { 5. Desintegración familiar. } \\
\text { 6. Drogadicción. } \\
\text { 7. Muerte. }\end{array}$ \\
\hline
\end{tabular}

Fuente: Elaboración propia, 2016.

Antecedentes de la regulación contra la legitimación de capitales provenientes de actividades ilícitas

En Costa Rica se han creado leyes y normativa para luchar contra el problema de la legitimación de activos. En el cuadro 2 se resumen algunas de las diferentes iniciativas legales existentes hasta el momento. Por tanto, es posible comprobar que el tema ha sido de suma importancia para diferentes gobiernos, además del grado de compromiso que se ha tenido en la lucha de tan repudiable flagelo. 
CUADRO 2

Resumen normativa legitimación de activos y financiamiento al terrorismo

\begin{tabular}{|c|c|c|}
\hline Documento & Fechas & Aspectos importantes \\
\hline $\begin{array}{l}\text { Ley Sobre Estupefacientes, } \\
\text { Sustancias Psicotrópicas, } \\
\text { Drogas de Uso No } \\
\text { Autorizado y Actividades } \\
\text { Conexas. Ley } 7093 .\end{array}$ & $\begin{array}{l}\text { Aprobada el } 22 \text { de abril de } \\
\text { 1988, entró en vigencia el } \\
2 \text { de mayo de } 1988\end{array}$ & $\begin{array}{l}\text { - Se tipifica el delito de la legitimación de capitales. } \\
\text { - Se establece obligatoriedad de declarar el ingreso de dinero al país. } \\
\text { - Se crea el CICAD actualmente Instituto Costarricense Sobre Drogas } \\
\text { (ICD). } \\
\text { - Se establece sanción a funcionarios públicos que por culpa favorecie- } \\
\text { ran la impunidad de los delitos. } \\
\text { - Se instaura la posibilidad del comiso. }\end{array}$ \\
\hline $\begin{array}{l}\text { Reforma Ley de } \\
\text { Estupefacientes, Sustancias } \\
\text { Psicotrópicas, Drogas } \\
\text { de Uso No Autorizado } \\
\text { y Actividades Conexas. } \\
\text { Ley } 7233\end{array}$ & $\begin{array}{l}\text { Aprobada el } 8 \text { de mayo de } \\
1991 \text {, entró en vigencia el } \\
21 \text { de mayo de } 1991\end{array}$ & $\begin{array}{l}\text { - Se adiciona un inciso 12) en el artículo } 93 \text { del Código Penal y se dero- } \\
\text { gan los artículos } 265 \text { y } 267 \text { del mismo Código. } \\
\text { - No se realizan modificaciones al tema de la legitimación de capitales. }\end{array}$ \\
\hline $\begin{array}{l}\text { Ley Sobre Estupefacientes, } \\
\text { Sustancias Psicotrópicas, } \\
\text { Drogas de Uso No } \\
\text { Autorizado y Actividades } \\
\text { Conexas. Ley } 7786\end{array}$ & $\begin{array}{l}\text { Aprobada el } 30 \text { de abril } \\
\text { de } 1988, \text { publicada en el } \\
\text { Alcance } n^{\circ} 15 \text { de La Ga- } \\
\text { ceta } n^{\circ} 93 \text { del } 15 \text { de mayo } \\
\text { de } 1998\end{array}$ & $\begin{array}{l}\text { - Se establecen obligaciones para las instituciones financieras, bursátiles } \\
\text { - Se implementiones. } \\
\text { - Se instaura el cumplimiento de la Ley por parte de las entidades regu- } \\
\text { ladas por las Superintendencias. } \\
\text { - Se establece requerimientos de identificación de clientes y manteni- } \\
\text { miento de registros. } \\
\text { - Registro y notificación de transacciones en efectivo, únicas y múltiples, } \\
\text { iguales o superiores a US\$10.000.00. } \\
\text { - Se establece la comunicación de transacciones sospechosas. } \\
\text { - Se fijan sanciones por culpa a los funcionarios de entes fiscalizadores o } \\
\text { fiscalizados y sanciones administrativas. } \\
\text { - Se crea la Unidad de Análisis Financiero del CICAD. }\end{array}$ \\
\hline
\end{tabular}




\section{Documento}

Fechas

Aspectos importantes

Ley Sobre Estupefacientes, Aprobada 17 de diciembre Sustancias Psicotrópicas, Drogas de Uso No Autorizado y Actividades Conexas. Ley 8204. del 2001, rige a partir de su publicación en La Gaceta $\mathrm{n}^{\circ} 8$, del 11 de enero del 2002, modifica la Ley $n^{\circ} 7786$
- Se amplían las sanciones a los funcionarios quienes tanto por dolo o culpa faciliten directa o indirectamente la comisión de algún ilícito relacionado.

- Se amplía la legitimación de capitales a otros delitos graves.

- Se incluyen los fideicomisos dentro de las entidades fiscalizadas pero se excluyeron empresas no financieras de la obligación de reporte.

- Se creó el Instituto Costarricense sobre Drogas.

- Se dictaron los siguientes lineamientos y obligaciones:

- Identificación y mantenimiento de registros de los clientes e impedimento de mantener cuentas anónimas o cifradas.

- Cumplimiento de forma inmediata de solicitudes de información de jueces de la República (artículo 17)

- Registro y notificación de transacciones, únicas y múltiples, en efectivo por montos superiores a $\$ 10000.00$ o su equivalente en moneda nacional

- Se define el concepto de transacción sospechosa y establece deber de comunicación a los entes supervisores.

- Obligación de adoptar, desarrollar y ejecutar programas y controles para prevenir y detectar los delitos tipificados en la ley de Psicotrópicos.

- Desarrollo de programas permanentes de capacitación del personal.

- Nombramiento del Oficial de Cumplimiento y la obligación de la administración de brindar los medios para cumplir con su labor.

- Delimita las penas a que se exponen los colaboradores, alta administración y directores. 


\begin{tabular}{|c|c|c|}
\hline Documento & Fechas & Aspectos importantes \\
\hline $\begin{array}{l}\text { Reglamento General a la } \\
\text { Ley Sobre Estupefacientes, } \\
\text { Sustancias Psicotrópicas, } \\
\text { Drogas de Uso No } \\
\text { autorizado, Legitimación } \\
\text { de Capitales y Actividades } \\
\text { Conexas }\end{array}$ & $\begin{array}{l}\text { Publicado en el Alcance } \\
10 \text { del diario oficial La } \\
\text { Gaceta n }{ }^{\circ} 51 \text { del } 12 \text { de } \\
\text { marzo de } 2004\end{array}$ & $\begin{array}{l}\text { - Se crea la Comisión de Asesoramiento contra la Legitimación de Capi- } \\
\text { tales y señala las funciones que tendrá dicha comisión. } \\
\text { - Establece la obligación de contar con perfiles de los clientes que } \\
\text { permita de determinar el tipo, número, volumen y frecuencia, de las } \\
\text { operaciones, productos o servicios que posteriormente se reflejarán en } \\
\text { la cuenta del cliente. } \\
\text { - Prohíbe mantener relaciones directas o indirectas, con bancos pantalla. } \\
\text { - La entidad debe contar con programas informáticos que permitan } \\
\text { determinar todas aquellas operaciones que se desvín de los pará- } \\
\text { metros previamente determinados en el perfil del cliente al momento } \\
\text { de la apertura. } \\
\text { - Contar con procedimientos de revisión de las transferencias que se } \\
\text { realicen en el país y las recibidas y enviadas desde o hacia el exterior. } \\
\text { - Obliga a contar con un Manual de Cumplimiento aprobado por la } \\
\text { Junta Directiva General. } \\
\text { - Se debe nombrar un Oficial de Cumplimiento, con su respectivo } \\
\text { suplente, y organizar un Comité de Cumplimiento. } \\
\text { - Se debe emitir un Código de Ética que contenga pautas de comporta- } \\
\text { miento para prevenir el uso indebido de sus operaciones financieras. } \\
\text { - Define el papel de la Auditoria Interna en apoyo a la labor del Oficial } \\
\text { de Cumplimiento. } \\
\text { - Los contratos con los auditores externos deben incluir obligatoriamen- } \\
\text { te una evaluación del cumplimiento de lo dispuesto por la Ley } 8204 \text {. }\end{array}$ \\
\hline $\begin{array}{l}\text { Normativa para el } \\
\text { Cumplimiento de la Ley } \\
\text { Sobre Estupefacientes, } \\
\text { Sustancias Psicotrópicas, } \\
\text { Drogas de Uso No } \\
\text { Autorizado, Legitimación } \\
\text { de Capitales y Actividades } \\
\text { Conexas }\end{array}$ & $\begin{array}{l}\text { Publicada en la Gaceta } \\
\mathrm{n}^{\circ} 133 \text { del } 08 \text { de julio del } \\
\text { 2004, rige a partir del } 08 \\
\text { de octubre del } 2004\end{array}$ & $\begin{array}{l}\text { - Se crea la Comisión que amplía los aspectos descritos en el Regla- } \\
\text { mento para la aplicación de la Ley } 8204 \text { en cuanto a determinación de } \\
\text { responsabilidades y pautas de realización y requisitos. } \\
\text { - Entre los requisitos mínimos se incluyen los siguientes: } \\
\text { - Manual de Cumplimiento. } \\
\text { - Conocimiento del cliente y del personal. } \\
\text { - Registro y notificación de transacciones. } \\
\text { - Oficial y Comité de Cumplimiento. }\end{array}$ \\
\hline
\end{tabular}




\begin{tabular}{|c|c|c|}
\hline Documento & Fechas & Aspectos importantes \\
\hline $\begin{array}{l}\text { Fortalecimiento de la } \\
\text { Legislación Contra el } \\
\text { Terrorismo. Ley } 8719\end{array}$ & $\begin{array}{l}\text { Aprobada el } 4 \text { de marzo } \\
\text { del } 2009 \text {, rige a partir } \\
\text { de su publicación en La } \\
\text { Gaceta }{ }^{\circ} 52 \text {, del } 16 \text { de } \\
\text { marzo del } 2009 \text {, modifica } \\
\text { la Ley } N^{\circ} 8204\end{array}$ & $\begin{array}{l}\text { - Se incluye el financiamiento al terrorismo. } \\
\text { - Se deben revisar las listas de personas y organizaciones ligadas con el } \\
\text { terrorismo (implica inmovilización de los productos financieros). } \\
\text { - Se incluye a la Superintendencia General de Seguros (SUGESE) como } \\
\text { ente supervisor y fiscalizador. } \\
\text { - Se amplía la legitimación de capitales a otros delitos graves. } \\
\text { - Se incluye a las remesadoras como sujeto obligado. } \\
\text { - Obligación del cliente de firmar el formulario de la política "Conozca } \\
\text { a su Cliente". } \\
\text { - Imposibilidad para los sujetos regulados de abrir cuentas y mantener } \\
\text { como clientes a sociedades con acciones al portador. } \\
\text { - Amplía la obligatoriedad de registrar el ingreso o egreso de las tran- } \\
\text { sacciones, únicas o múltiples, (no solamente en efectivo) en moneda } \\
\text { nacional o extranjera, igual o superior a US\$10 000 } 00 \text { o su equivalente } \\
\text { en colones. } \\
\text { - Se crea el "puerto seguro" para las entidades o funcionarios quienes } \\
\text { comuniquen reportes de operaciones sospechosas. } \\
\text { - Se elimina la obligación del ICD y los órganos de fiscalización y super- } \\
\text { visión, de poner en conocimiento del Ministerio Público información } \\
\text { referente a operaciones sospechosas. } \\
\text { - Obligación de presentar y declarar el dinero efectivo o títulos valores } \\
\text { que porte al ingresar o salir del país (igual o superior a los US\$10 } 000 \\
00 \text { so pérdida inmediata del dinero o los valores a favor del ICD. } \\
\text { - Amplía las sanciones patrimoniales para las instituciones reguladas de } \\
0,05 \% \text { a } 1 \% \text { y de } 1 \% \text { a } 2 \% \text {. }\end{array}$ \\
\hline $\begin{array}{l}\text { Normativa para el } \\
\text { Cumplimiento de la Ley } \\
\text { Sobre Estupefacientes, } \\
\text { Sustancias Psicotrópicas, } \\
\text { Drogas de Uso No } \\
\text { Autorizado, Legitimación } \\
\text { de Capitales y Actividades } \\
\text { Conexas }\end{array}$ & $\begin{array}{l}\text { Publicada en el Diario } \\
\text { Oficial La Gaceta No. } \\
248 \text { del } 22 \text { de diciembre } \\
\text { del } 2010\end{array}$ & $\begin{array}{l}\text { - Se establece que la gestión del riesgo de LC/FT debe ser parte integral } \\
\text { del proceso de evaluación de riesgo. } \\
\text { - Se debe asignar una categoría de riesgo a cada cliente. } \\
\text { - Se establecen criterios o variables para el análisis y descripción del } \\
\text { perfil de riesgo de cada cliente (posibilidad de agregar otros criterios) } \\
\text { - El formulario "Conozca a su Cliente" debe ser firmado por el cliente. } \\
\text { - Actualización periódica de los documentos y datos, recopilados como } \\
\text { parte del conocimiento de los clientes. } \\
\text { - Los clientes deben ser entidades constituidas y registradas en su país de } \\
\text { origen de forma nominativa, sin acciones al portador. } \\
\text { - Identificación de PEPs. } \\
\text { - La inducción y capacitación impartida anualmente a todo el personal, } \\
\text { deben ser evaluadas. } \\
\text { - La auditoría externa debe incluir pruebas específicas sobre el cum- } \\
\text { plimiento de las medidas para prevenir y detectar la legitimación de } \\
\text { capitales y el financiamiento al terrorismo. }\end{array}$ \\
\hline
\end{tabular}




\begin{tabular}{|c|c|c|}
\hline Documento & Fechas & Aspectos importantes \\
\hline $\begin{array}{l}\text { Reglamento General sobre } \\
\text { Legislación Contra el } \\
\text { Narcotráfico, Actividades } \\
\text { Conexas, Legitimación de } \\
\text { Capitales, Financiamiento } \\
\text { al Terrorismo y } \\
\text { Delincuencia Organizada }\end{array}$ & $\begin{array}{l}\text { Publicada en el Diario } \\
\text { Oficial La Gaceta No. } 12 \\
\text { del } 17 \text { de enero del } 2012\end{array}$ & $\begin{array}{l}\text { - Se establecen las operaciones sustanciales y operaciones sistemáticas. } \\
\text { - Se establece la obligatoriedad de inscripción ante SUGEF de las perso- } \\
\text { cas para terceros. } \\
\text { - El formulario "Conozca a su Cliente" debe ser firmado por el cliente al } \\
\text { inicio de la relación comercial. } \\
\text { - Aplicación de una debida diligencia simplificada a los clientes con } \\
\text { cuentas de expediente simplificado. } \\
\text { - Establecimiento de procedimientos de diligencia reforzada para clien- } \\
\text { tes calificados como de alto riesgo e identificados como PEPs. } \\
\text { - Prohibición de mantener relaciones directas o indirectas con bancos } \\
\text { ficticios o bancos pantalla. } \\
\text { - Comunicación a la UIF sobre operaciones intentadas. } \\
\text { - Utilización de la plataforma SINPE por parte de las autoridades judi- } \\
\text { ciales y administrativas competentes con fines de investigación, análisis } \\
\text { y supervisión. }\end{array}$ \\
\hline $\begin{array}{l}\text { Normativa para el } \\
\text { Cumplimiento de la Ley } \\
\text { Sobre Estupefacientes, } \\
\text { Sustancias Psicotrópicas, } \\
\text { Drogas de Uso No } \\
\text { Autorizado, Legitimación } \\
\text { de Capitales y Actividades } \\
\text { Conexas }\end{array}$ & $\begin{array}{l}\text { Alcance Digital No. } 145 \\
\text { del } 17 \text { de agosto del } 2016\end{array}$ & $\begin{array}{l}\text { - Se modifican los artículos 1, 2, 3, 7, 8, 9, 10, 11, 12, 14, 19, 22, 23, } 27 \\
\text { bis, } 27 \text { ter, } 28 \text { y } 30 \text {. } \\
\text { - Se incluyen tres definiciones en el artículo 2, un nuevo artículo } 19 \text { bis. }\end{array}$ \\
\hline
\end{tabular}

Fuente: Elaboración propia. Datos tomados de la propia normativa vinculante, 2016.

\section{La dimensión del problema de Costa Rica}

Hay una realidad que no puede ser obviada. Según datos que emite la Comisión Económica para América Latina y el Caribe (CEPAL), durante el 2013, se indica que Costa Rica es el primer país latinoamericano con más lavado de capitales, tal como se muestra en la siguiente figura que compara ese fenómeno con otros países:

Sobre la definición de flujos financieros ilícitos, la CEPAL adoptando una definición utilizada en diversas investigaciones indica:

Los flujos financieros ilícitos son movimientos, de un país a otro, de dinero que ha sido ganado, transferido o utilizado de manera ilegal. En general, estos fondos se originan en las actividades comerciales (falsificación de la facturación del comercio y precios de transferencia abusivos), en actividades delictivas y en la corrupción. ${ }^{6}$

6. Comisión Económica para América Latina y el Caribe. Estudio Económico de América Latina y el Caribe 2016: La Agenda 2030 para el Desarrollo Sostenible y los desafios del financiamiento para el desarrollo. Santiago: Naciones Unidas, 2016. 
A. En millones de dólares

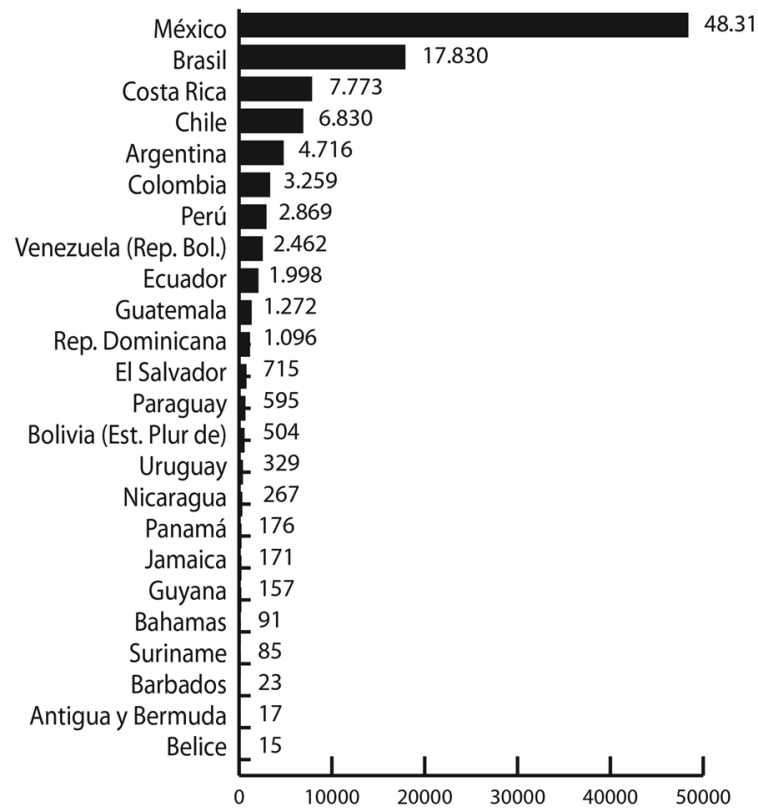

\section{B. En porcentajes del PIB}

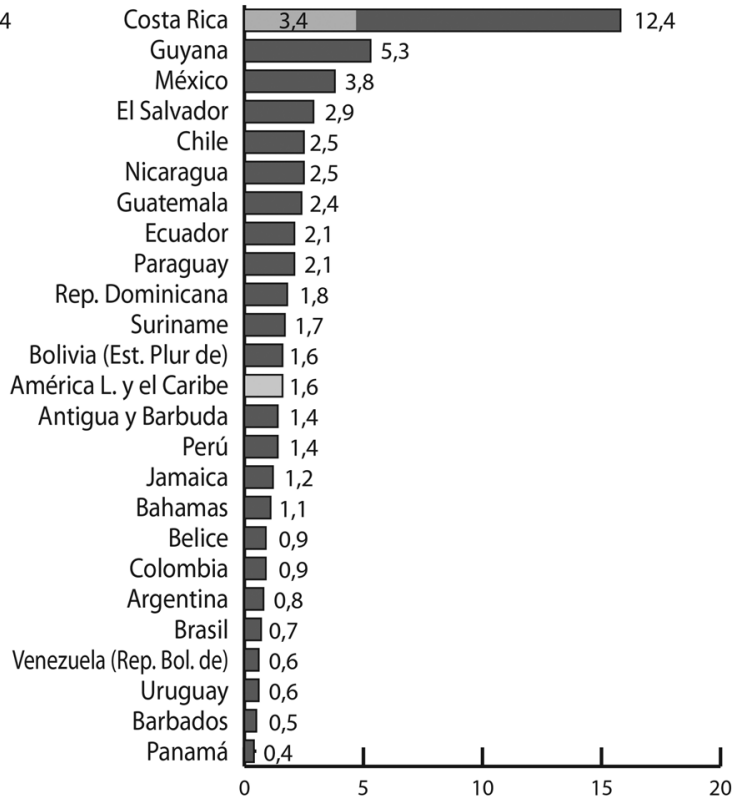

Figura 2. América Latina y el Caribe montos estimados de la manipulación de precios del comercio internacional de bienes, por país (2013) (En millones de dólares y en porcentajes del PIB). Fuente: Comisión Económica para América Latina y el Caribe (CEPAL).

En el informe señalado se incluyen términos como "blanqueo", "lavado" o "legitimación", pero es bien sabido que esos son sinónimos o actividades que generan recursos provenientes de los delitos financieros $\mathrm{u}$ actividades delictivas.

De esta manera, Costa Rica se encuentra en una lista gris que lo coloca en riesgo y, por tanto, de caída de inversión extranjera. La CEPAL indica que el país es uno de los líderes en América Latina en "flujos ilícitos".

El mismo informe menciona que se estima una fuga de dinero de aproximadamente \$7773 millones, ocasionando a su vez pérdidas tributarias de la región de aproximadamente \$ 31000 millones, 0,5 puntos del PIB, (Comisión Económica para América Latina y el Caribe 2016, 133 $)^{7}$

Asimismo, la CEPAL estima que cuatro mil millones de colones que se lavan desde Costa Rica, solo lo superan México y Brasil, e indica que la fuga de capitales tiene la intención de evadir controles internos o internacionales establecidos.

Según el Grupo de Acción Financiera (GAFI) estimó (cuándo y qué fundamento) que la ganancia global del crimen organizado con el blanqueo de capitales supera los dos billones de dólares al año y los principales problemas que señalan a Costa Rica y que facilitan el lavado de dinero son una legislación permisiva y poco control.

7. Comisión Económica para América Latina y el Caribe. Estudio Económico de América Latina y el Caribe 2016: La Agenda 2030 para el Desarrollo Sostenible y los desafios del financiamiento para el desarrollo. Santiago: Naciones Unidas, 2016. 
Varios problemas paralelos se desprenden de este delito, los cuales repercuten directamente en la estabilidad de la sociedad civil y en las estructuras del Estado en cuanto al incremento acelerado de la violencia, la lucha e inserción de los cárteles en el país y en instancias claves, el tráfico de armas, el aumento en los niveles de corrupción, hasta aspectos como sicariato, ajusticiamientos, corrupción, entre otros.

Desde el punto de vista de la estructura del estado, existen deficiencias que afectan la gestión misma de los procesos de control. Por ejemplo, al darse una trasferencia de responsabilidades preventivas a los bancos, se diluyen otras instancias o mecanismos de control del funcionamiento del Estado y los sectores vinculados. En otras palabras, la responsabilidad se diluye entre el sistema al ser asumido solo por una parte que, además, no trabaja en forma homogénea como sistema integrado y con canales cruzados de control.

Al ser Costa Rica un puente natural para América, esa particularidad la convierte en una zona de interés para el crimen organizado, en un paso de tránsito normal, no solamente para el tráfico de drogas, sino también para otros delitos relacionados, como contrabando de armas, lavado de activos, tráfico de personas, entre otros.

Estos problemas, eventualmente, traen como consecuencia directa la violencia y con esta la muerte, no solamente de personas vinculadas al crimen organizado, sino también de civiles inocentes. Por tanto, es necesario protegerse de la legitimación de activos, existen propuestas muy concretas y lecciones aprendidas de otros países. Sobre esto Pabla Barahona-Krüger indica:

Si bien retoman fuerza las voces que advierten un desequilibrio entre la levedad de las penas en delitos relacionados a corrupción y los delitos comunes, o lo que es igual, la desarmonía entre la penalidad impuesta a la macrocriminalidad y la microcriminalidad, el análisis de las penas implicaría todo un estudio aparte y muy especializado que no ha sido intentado siquiera en el presente informe, pero que podría ser objeto de futuras aplicaciones investigativas. ${ }^{8}$

La corrupción es un denominador común en muchos de los gobiernos del mundo, hemos visto como expresidentes, ministros, alcaldes, diputados y figuras vinculadas con el deporte costarricense, han caído víctima y han comprometido su independencia enrolándose en actividades delictivas.

Globalmente, se lucha contra el terrorismo y el narcotráfico, no podemos ser indiferentes ante nuestra realidad, todos debemos hacer nuestra parte frente al compromiso social y moral, debemos heredar a las futuras generaciones un mejor lugar, una mejor calidad de vida y una Costa Rica mejor y más segura.

Un mundo globalizado es un abanico de posibilidades para los criminales en donde pueden valerse de cualquier oportunidad que brinde cualquier país para legitimar activos. José Antonio Mateos Marín indica:

8. Pabla Barahona-Krüger,Los "blindajes" contra la corrupción y legitimación de activos en costa Rica. San José: Estado de La Nación, 2011. 
En cuanto a los métodos de blanqueo de capitales en los que se utilizan personas jurídicas, la delincuencia dedicada al blanqueo de capitales no cesa de buscar nuevas vías destinadas a dar apariencia de legalidad a los bienes obtenidos de forma ilícita, lo que provoca que quienes se dedican a su investigación tienen que tener suficiente amplitud de miras para descubrir las nuevas formas de blanquear que continuamente van surgiendo. ${ }^{9}$

Son muchos los casos sonados mundialmente en los que se vincula a Costa Rica como un país en el que desgraciadamente se ha demostrado que es posible legitimar activos, no es el objetivo de este trabajo mencionarlos o hablar de ellos, pero a modo de ejemplo analicemos las estadísticas presentadas por la organización no gubernamental Integridad Financiera Global (Global Financial Integrity), en la que es posible observar que año con año el flujo de dinero ilícito en nuestro país aumenta exponencialmente.

La organización presenta datos nada halagüeños para nuestro país, en su informe más reciente se calcula que para el periodo comprendido entre 2003 y 2012 en nuestro país se movilizaron $\$ 94034$ millones, promediando anualmente una cifra nada despreciable de $\$ 9403$ millones, presentando una variación aproximada de 21\% entre el 2012 y el 2011.

Flujos financieros ilícitos estimados para países en desarrollo 2003-2012 (en millones de dólares)

\begin{tabular}{lcccccccccccc}
\multicolumn{1}{c}{ País } & 2003 & 2004 & 2005 & 2006 & 2007 & 2008 & 2009 & 2010 & 2011 & 2012 & Acumulado & Promedio \\
México & 38,084 & 40,740 & 47,747 & 48,086 & 58,618 & 65,489 & 37,192 & 65,570 & 53,078 & 59,656 & 514,259 & 51,426 \\
Brasil & 12,069 & 15,897 & 16,782 & 10,681 & 17,264 & 21,765 & 22,324 & 32,289 & 34,105 & 33,928 & 217,103 & 21,710 \\
Costa Rica & 3,440 & 4,640 & 5,274 & 5,378 & 5,539 & 6,821 & 8,734 & 14,828 & 17,829 & 21,553 & 94,034 & 9,403 \\
Panamá & 2,414 & 2,716 & 3,950 & 4,649 & 5,565 & 5,838 & 5,351 & 5,712 & 6,946 & 5,341 & 48,481 & 4,848 \\
Chile & 2,534 & 2,614 & 4,318 & 4,548 & 4,125 & 7,594 & 3,303 & 5,411 & 6,110 & 5,082 & 45,639 & 4,564 \\
Honduras & 2,722 & 2,920 & 3,175 & 3,355 & 3,388 & 3,294 & 2,981 & 3,530 & 3,701 & 3,872 & 32,939 & 3,294 \\
Ecuador & 20 & 862 & 1,972 & 1,235 & 1,236 & 6,097 & 1,159 & 376 & 1,562 & 1,929 & 16,448 & 1,645 \\
Nicaragua & 625 & 1,055 & 1,019 & 1,384 & 1,302 & 1,264 & 1,198 & 1,730 & 2,666 & 2,851 & 15,094 & 1,509 \\
Rep. Dominicana & 1,886 & 981 & 456 & 888 & 348 & 1,099 & 1,431 & 2,187 & 1,040 & 1,733 & 12,050 & 1,205 \\
Guatemala & 1,377 & 1,400 & 1,623 & 911 & 1,020 & 920 & 822 & 1,485 & 618 & 1,588 & 11,764 & 1,176 \\
El Salvador & 642 & 657 & 1,064 & 930 & 1,022 & 878 & 908 & 932 & 664 & 177 & 7,875 & 788 \\
\hline
\end{tabular}

Figura 3. Etapas del lavado de dinero. Fuente: Illicit Financial Flows from Developing Countries: 2003-2012. Global Financial Integrity. Tomado del Semanario Universidad (Estrada Pimentel 2015).

Recientemente, el gobierno de EE.UU. ha externado que duda de que Costa Rica pueda encarar el creciente lavado de dinero, incluso replicó el dato estimado por la Dirección de Inteligencia y Seguridad Nacional (DIS), en el cual se indica que anualmente en nuestro país se blanquearían unos $\$ 4,2$ billones producto de actividades ilícitas como el narcotráfico (Departamento de Estado de los Estados Unidos de Norteamérica 2016).

La capacidad del sistema costarricense es puesta en duda sobre todo cuando se trata de enfrentar las actividades del crimen organizado, por eso el vínculo, la

9. José Antonio Mateos-Marín, «El reto de la prevención del blanqueo de capitales en un mundo globalizado.» Revista de Derecho UNED, 2013: 243-493. 
internacionalización y la preponderancia de los delitos mantienen muy preocupado al gobierno estadounidense.

Ese reporte desnuda deficiencias de nuestro país (Departamento de Estado de los Estados Unidos de Norteamérica 2016):

1. Las organizaciones criminales transnacionales ven cada vez más en Costa Rica una base favorable para cometer delitos financieros, incluido el blanqueo de dinero, como consecuencia de su ubicación geográfica y otros factores, incluyendo la capacidad de aplicación limitada. Esta tendencia plantea serias preocupaciones sobre la capacidad del gobierno para evitar que estas organizaciones se infiltren aún más en la economía.

2. Gran parte del lavado de dinero se canaliza a través de la incipiente industria de la construcción. Otros sectores fueron identificados como vulnerables a la explotación por parte de las organizaciones criminales que tratan de blanquear el producto ilícito, incluyendo el Estado e instituciones financieras privadas. También los servicios de transferencia de dinero, la industria de los casinos y el sector inmobiliario. Así como las diversas operaciones de juegos en línea con sede en Costa Rica lavan millones de dólares en ganancias ilícitas.

3. La escasez de condenas y sanciones plantea preocupaciones con respecto a la capacidad de Costa Rica de detectar con eficacia, prevenir, investigar y enjuiciar los delitos de lavado de dinero; así como combatir las organizaciones criminales sofisticadas que operan.

4. Costa Rica no tiene un marco legal adecuado para el decomiso de activos sin condena. Propuestas legislativas recientes podrían corregir esta deficiencia y mejorar la capacidad de desmantelar las organizaciones criminales.

5. Diversas operaciones de juego en línea con sede en Costa Rica lavan millones de dólares en ganancias ilícitas a través del país y en offshore anualmente. Las autoridades también han detectado; sin embargo, con menos frecuencia, esquemas de lavado de dinero basado en el comercio. No ha habido procesamientos relacionados con el financiamiento al terrorismo. Además, las medidas para detectar, investigar y enjuiciar este tipo de financiación son limitadas.

El mismo informe indica sectores en Costa Rica que están en la mira por lavado de activos:

- Casas de cambio y remesadores de dinero

- $\quad$ Agentes de valores

- Dadores de crédito

- Vendedores o cambistas de cheques de viajero y giros postales

- Administradores e intermediarios financieros

- Gestores de activos 
- Desarrolladores y agentes de bienes raíces

- Fabricantes, vendedores y distribuidores de armas; arte, joyas, metales preciosos y los comerciantes

- Vendedores de vehículos nuevos y usados

- Casinos, casinos virtuales y entidades de juegos electrónicos

- Abogados y contadores

\section{Conclusiones}

Es posible demostrar que la legitimación de activos representa un problema que debilita gobiernos, afecta economías, deteriora a la sociedad, genera corrupción y aumentos significativos en la violencia, por ende contribuye a la inseguridad ciudadana, aun cuando las autoridades policiales hagan sus mayores esfuerzos para combatirlo.

El combate contra la legitimación de activos no debe ser exclusivo de nuestras autoridades administrativas y judiciales, tampoco de nuestros legisladores, todos y cada uno de los ciudadanos, independientemente del país donde nos encontremos, debemos ser parte de esta lucha.

Es primordial mejorar la imagen del país ante los evaluadores internacionales, dado que lo constatado por ellos es sustancialmente tangible y demostrable, sobre todo para evitar ser incluidos en listas negras o ahora normalmente llamadas listas grises.

Debe darse prioridad a la atención de los hallazgos hechos por el Grupo de Acción Financiera de Latinoamérica (GAFILAT), en donde puntualmente se indican deficiencias u, desde un pensamiento positivista, oportunidades de mejora, estos a final de cuenta determinan o inspiran las calificaciones y el riesgo país de Costa Rica. Entre las observaciones se pueden citar:

Deficiencias en la adecuada tipificación del delito del financiamiento al terrorismo que pueden afectar la efectividad en materia de la lucha en su contra.

Insuficiente información relacionada con la retroalimentación sobre la eficacia y calidad de la cooperación o información provista por parte de los países. Baja cooperación internacional realizada por los supervisores de los sujetos obligados.

Existe una proliferación de actividades informales de remesas, cambio de divisas, préstamos de dinero, así como dificultad para obtener información sobre los beneficiarios finales por parte de las autoridades.

Falta de un registro específico para los fideicomisos y estructuras jurídicas donde consten las condiciones del contrato, no se evidencia la retroalimentación por parte de las autoridades competentes hacia la Unidad de Información Financiera.

Debemos ser conscientes de que con el compromiso de todos podemos acabar con la drogadicción, la corrupción y la violencia, no solamente educando a nuestros hijos con 
buenos valores morales, no solo enseñándoles el valor de la vida y la dignidad humana, el amor y el respeto al trabajo digno y al esfuerzo propio.

Debemos ser más responsables con nuestras decisiones comerciales que contribuyen a la permanencia de esta actividad delictiva, debemos conocer bien con quién hacemos negocios, quién administra nuestros bienes, a quién compramos y a quién vendemos, no debemos prestarnos para que nos usen como parte de las tramas complejas o sencillas de la legitimación.

Esta lucha es de todos y por eso es que todos somos responsables, cada uno en lo suyo, pero al final jalando parejo el carro de la justicia, la igualdad y la seguridad social nuestra, de nuestros vecinos y de las futuras generaciones.

En el tanto de que el crimen organizado siga contando con los flujos de dinero necesarios para financiar sus guerras, sobornar gobiernos y entes policiales, pagar sicarios, amedrentar a los ciudadanos, llevar las drogas y la violencia a todos los lugares de nuestros países, es y será la prevención de la legitimación de activos una responsabilidad de todos.

\section{ABSTRACT}

Asset Laundering: The Costa Rican Experience

The purpose of this paper is to demonstrate that asset legitimation portrays a problem that weakens governments, affects economies, deteriorates society, generates corruption and significant increase in violence; consequently, it affects civic unsafety, even when the police force does their best effort to fight this calamity. All citizens must understand that eventually they can suffer the consequences of this problem and they must be willing to do their part to fight this disaster. The international fight against asset laundering demonstrates that it can be defeated when everyone promotes awareness and recognizes their own values and individual contribution; these are the most powerful weapons to fight this evil.

Key words: legitimation, asset, drug, drug trafficking, laundry, money, society, security, problems, prevention.

\section{RÉSUMÉ}

\section{Le blanchiment d'argent: l'expérience costaricienne}

Ce travail a pour but de démontrer que le blanchiment d'argent représente un problème qui affaiblit le gouvernement, pollue l'économie, détériore la société, favorise la corruption et augmente significativement la violence; par conséquent, il contribue à l'insécurité sociale même si les autorités policières luttent contre ce fléau. Tout citoyen doit être capable de comprendre qu'il peut subir les conséquences du problème, c'est pourquoi il faut être conscient de son rôle dans cette lutte. La lutte internationale contre le blanchiment des capitaux d'origine illicite met en évidence que la participation active de chaque personne est la seule manière de gagner au travers de la conscience, de la reconnaissance de ses valeurs et de son apport. Ces dispositifs sont les armes les plus puissantes dans la lutte de contre ce mal.

Mots-clés: légitimation, capitaux, trafic de drogues, blanchiment, argent, société, insécurité, problématique, prévention. 


\section{Referencias}

Asociación de Especialistas Certificados en Antilavado de Dinero. Guía de estudio para el examen de certificación CAMS. Cuarta. Miami: ACAMS, 2007.

Barahona- Krüger, Pabla. Los “blindajes" contra la corrupción y legitimación de activos en costa Rica. San José: Estado de La Nación, 2011.

Comisión Económica para América Latina y el Caribe. Estudio Económico de América Latina y el Caribe 2016. La Agenda 2030 para el Desarrollo Sostenible y los desafíos del financiamiento para el desarrollo. Santiago: Naciones Unidas, 2016.

del Cid-Gómez, Juan Miguel. «Prevención del blanqueo de capitales. Un enfoque basado en el riesgo para contables externos y asesores fiscales.» Partida Doble, 2009: 74-81.

Departamento de Estado de los Estados Unidos de Norteamérica. Diplomacia en acción. 11 de Marzo de 2016. http://www.state.gov/j/inl/rls/nrcrpt/2016/vol2/253393.htm (último acceso: 9 de Marzo de 2016).

Estrada- Pimentel, María. «Costa Rica entre los mayores paraísos de capitales ilícitos.» Semanario Universidad 2112 (Noviembre, 2015): 4-5.

González, Lubi, Edwards Carvajal y Linda Chacín. «Líneas de acción aplicadas en la prevención y control de la legitimación de capitales en la banca universal venezolana.» Revista COEPTUM, 2014: 1-14.

Mateos- Marín, José Antonio. «El reto de la prevención del blanqueo de capitales en un mundo globalizado.» Revista de Derecho UNED, 2013: 243-493.

Pontón, Daniel. «La economía del narcotráfico y su dinámica en América Latina.» Revista de Ciencias Sociales, 2013: 135-153.

República de Costa Rica. Fortalecimiento de la Legislación Contra el Terrorismo. Ley 8719. San José: Asamblea Legislativa, 2009.

Ley Sobre Estupefacientes, Sustancias Psicotrópicas, Drogas de Uso No Autorizado y Actividades Conexas. Ley 7093. San José: Asamblea Legislativa, 1988.

Ley Sobre Estupefacientes, Sustancias Psicotrópicas, Drogas de Uso No Autorizado y Actividades Conexas. Ley 7786. San José: Asamblea Legislativa, 1998.

Ley Sobre Estupefacientes, Sustancias Psicotrópicas, Drogas de Uso No Autorizado y Actividades Conexas. Ley 8204. San José: Asamblea Legislativa, 2002.

Normativa para el Cumplimiento de la Ley Sobre Estupefacientes, Sustancias Psicotrópicas, Drogas de Uso No Autorizado, Legitimación de Capitales y Actividades Conexas. San José: Asamblea Legislativa, 2004.

Normativa para el Cumplimiento de la Ley Sobre Estupefacientes, Sustancias Psicotrópicas, Drogas de Uso No Autorizado, Legitimación de Capitales y Actividades Conexas. San José: Asamblea Legislativa, 2010 .

Reforma Ley de Estupefacientes, Sustancias Psicotrópicas, Drogas de Uso No Autorizado y Actividades Conexas. Ley 7233. San José: Asamblea Legislativa, 1991.

Reglamento General a la Ley Sobre Estupefacientes, Sustancias Psicotrópicas, Drogas de Uso No autorizado, Legitimación de Capitales y Actividades Conexas. San José: Asamblea Legisltaiva, 2004.

Soto- Arroyo, Hannia. «El delito de legitimación de capitales a la luz de la legislación y la jurisprudencia penal costarricense.» Revista Electrónica de la Facultad de Derecho, ULACIT, 2012: 59-81. 